\section{Smoking, age, and laryngeal height predicted obstructive airway disease in adults}

Straus SE, McAlister FA, Sackett DL, et al, for the CARE-COAD1 Group. The accuracy of patient history, wheezing, and laryngeal measurements in diagnosing obstructive airway disease. JAMA 2000 Apr 12;283:1853-7.

\section{QUESTION: How accurate are the clinical examination and patient history in the diagnosis of obstructive airway disease (OAD)?}

\section{Design}

Blinded comparison of items from the clinical examination and patient history (self reported OAD, smoking history, wheezing on auscultation, maximum and minimum laryngeal height, and laryngeal descent) with spirometric results $\left(\mathrm{FEV}_{1}\right.$ and $\mathrm{FEV}_{1}-\mathrm{FVC}$ ratio 5th centile).

\section{Setting}

20 investigator groups in primary, secondary, and tertiary care centres in 14 countries.

\section{Patients}

332 patients were recruited, and 309 (mean age $56 \mathrm{y}$, $57 \%$ men, $89 \%$ white) were included in the analysis. Patients were recruited so that approximately one third had confirmed OAD, one third had suspected OAD, and one third had no evidence of OAD. Exclusion criteria were reversible airway obstruction, terminal illness, age $<18$ years, severe respiratory distress, or inability to obtain spirometry.

\section{Description of tests and diagnostic standard}

Clinical examination items were derived from previous research and consensus: self reported history of chronic $\mathrm{OAD}$, smoking history, laryngeal height and descent, and wheezing on auscultation. Spirometry was done within 30 minutes of clinical examination with the better attempt of 2 efforts recorded. OAD was confirmed if $\mathrm{FEV}_{1}$ and the $\mathrm{FEV}_{1}-\mathrm{FVC}$ ratio were $<5$ th centile. Spirometrists and clinicians were blinded.

\section{Main outcome measures}

Positive and negative likelihood ratios (+ LRs, -LRs) using multivariate analysis.

\section{Main results}

The reduced multivariate analysis indicated 4 items that, when all were present, were highly predictive of OAD in all patients: self reported chronic OAD, smoking $>40$ pack years, age $\geqslant 45 \mathrm{y}$, and maximum laryngeal height $\leqslant 4 \mathrm{~cm}$. The presence of 3 items predicted OAD in patients with no history of OAD: smoking $>40$ pack years, age $\geqslant 45 \mathrm{y}$, and maximum laryngeal height $\leqslant 4 \mathrm{~cm}$ (LRs in the table ). Wheezing and laryngeal descent were not predictive of OAD.

\section{Conclusion}

Obstructive airway disease was highly likely in the presence of smoking $>40$ pack years, age $\geqslant 45$ years, maximum laryngeal height $\leqslant 4 \mathrm{~cm}$, and self reported history of OAD.

Sources of funding: UK National Health Service Research and Development

Programme and Medical Research Council of Canada.

For correspondence: Dr F A McAlister, Division of General Internal Medicine, 2E3.24 Walter Mackenzie Centre, University of Alberta Hospital, 8440112 Street, Edmonton, Alberta T6G 2R7, Canada.Fax +1780 4072680.

Multivariate likelihood ratios (LRs) calculated from clinical examination and history for diagnosis of obstructive airway disease $(O A D)^{*}$

\begin{tabular}{|c|c|c|c|c|}
\hline \multirow[b]{2}{*}{ Diagnostic elements } & \multicolumn{2}{|c|}{ All patients } & \multicolumn{2}{|c|}{ Patients without known OAD } \\
\hline & +LR & -LR & $+\mathrm{LR}$ & $-\mathrm{LR}$ \\
\hline Self reported history of OAD & 7.3 & 0.5 & Not applicable & Not applicable \\
\hline Smoking $>40$ pack-years & 8.3 & 0.8 & 11.6 & 0.9 \\
\hline Age $\geqslant 45$ year & 1.3 & 0.4 & 1.4 & 0.5 \\
\hline Maximum laryngeal height $\leqslant 4 \mathrm{~cm}$ & 2.8 & 0.8 & 3.6 & 0.7 \\
\hline All factors present & 221 & 0.13 & 59 & 0.3 \\
\hline
\end{tabular}

*LRs defined in glossary.

\section{COMMENTARY}

The Clinical Assessment of the Reliability of the Examination (CARE) investigators have used the internet to recruit consecutive patients with a range of OAD likelihoods. The spirometric criteria for OAD differ from the commonly used Thoracic Societies criteria, but are sound. The process and criteria for excluding patients with asthma from the study are uncertain, but they may be important because airways disease includes a spectrum of reversibility. A similar process of excluding patients with asthma in clinical practice is necessary for the reported nomogram to retain external validity. Intraobserver and interobserver variations were not measured, but they may be important because a similar study showed only marginal agreement among observers. ${ }^{1}$ The study, however, provides important utility data for each of the clinical features tested, 2 of which can now be confidently removed from clinical practice when determining the likelihood of $\mathrm{OAD}$, namely, wheezing on auscultation and laryngeal descent.

The ability to rule out $\mathrm{OAD}$ is also important for the use of pulmonary function test resources. Comparison between the nomogram and clinicians' judgment would now be interesting. For example, a patient who is a non-smoker and $<45$ years old and who denies a history of $\mathrm{OAD}$ may either have $\mathrm{OAD}$ ruled out using clinical judgment or be sent for pulmonary function testing. Patients with an intermediate probability of OAD will benefit most from the nomogram.

Internet use for recruitment of $>300$ patients in 1 month, with a very low data error rate, is impressive. Future CARE reports are awaited with interest because they may affect not only the interpretation of diagnostic tests once clinical pretest likelihoods have been determined but also the economical use of diagnostic tests.

Brian J Smith, MBBS North West Adelaide Health Services Woodville, South Australia, Australia

1 Holleman DR Jr, Simel DL, Goldberg JS.J Gen Intern Med 1993;8:63-8. 